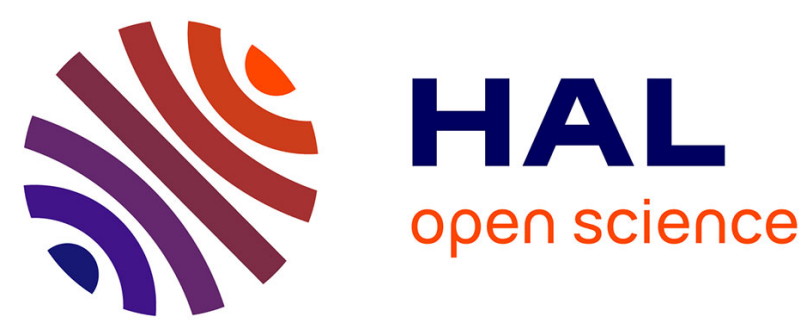

\title{
Reduced PPAR $\gamma 2$ expression in adipose tissue of male rat offspring from obese dams is associated with epigenetic modifications
}

Simon Lecoutre, Charlène Pourpe, Laura Butruille, Lucie Marousez, Christine Laborie, Céline Guinez, Jean J. Lesage, Didier D. Vieau, Jerome Eeckhoute, Anne Gabory, et al.

\section{To cite this version:}

Simon Lecoutre, Charlène Pourpe, Laura Butruille, Lucie Marousez, Christine Laborie, et al.. Reduced PPAR $\gamma 2$ expression in adipose tissue of male rat offspring from obese dams is associated with epigenetic modifications. FASEB Journal, 2018, 32 (5), pp.2768-2778. 10.1096/fj.201700997R . hal-02322973

\section{HAL Id: hal-02322973 \\ https://hal.science/hal-02322973}

Submitted on 23 Oct 2019

HAL is a multi-disciplinary open access archive for the deposit and dissemination of scientific research documents, whether they are published or not. The documents may come from teaching and research institutions in France or abroad, or from public or private research centers.
L'archive ouverte pluridisciplinaire HAL, est destinée au dépôt et à la diffusion de documents scientifiques de niveau recherche, publiés ou non, émanant des établissements d'enseignement et de recherche français ou étrangers, des laboratoires publics ou privés. 
3 Simon Lecoutre ${ }^{1}$, Charlène Pourpe ${ }^{1}$, Laura Butruille ${ }^{1}$, Lucie Marousez ${ }^{1}$, Christine Laborie

$4{ }^{1}$, Céline Guinez ${ }^{1}$, Jean Lesage ${ }^{1}$, Didier Vieau ${ }^{1}$, Jérôme Eeckhoute ${ }^{3}$, Anne Gabory ${ }^{2}$, 5 Frederik Oger ${ }^{1}$, Delphine Eberlé ${ }^{1}$ and Christophe Breton ${ }^{1}$

6

${ }^{1}$ Univ. Lille, EA4489, Equipe Malnutrition Maternelle et Programmation des Maladies Métaboliques, F-59000 Lille, France.

${ }^{2}$ UMR BDR, INRA, ENVA, Université Paris Saclay, 78350, Jouy-en-Josas, France.

${ }^{3}$ Univ. Lille, Inserm, CHU Lille, Institut Pasteur de Lille, U1011-EGID, F-59000 Lille, France.

\section{Corresponding author: Professor Christophe Breton}

Univ. Lille, EA4489, Équipe Malnutrition Maternelle et Programmation des Maladies Métaboliques, F-59000 Lille, France

Tel : +33 320436532 ; Fax : +33320336349

E-mail : christophe.breton@univ-lille1.fr

Short title: epigenetic modifications and PPAR $\gamma 2$ programming 0 (1) 


\section{Abbreviations}

AdipoQ: adiponectin

ACOX1: Peroxisomal acyl-coenzyme A oxidase 1

CD36: fatty acid translocase

ChIP: Chromatin immunoprecipitation

$\mathrm{C} / \mathrm{EBP} \alpha$ : CCAAT/enhancer binding protein alpha

DNMT: DNA methyltransferase

DOHaD: Developmental Origin of Health and Disease

DGAT2: diglyceride acyltransferase

FABP4: fatty acid binding protein 4

FAS: fatty acid synthase

GC: glucocorticoid

GLUT4: Glucose transporter type 4

HAT: histone acetyltransferase

HDAC: histone deacetylase

KAT2: lysine acetyltransferase 2A

LPL: lipoprotein lipase

MBD: methyl-binding domain

5hmC: 5-hydroxymethylcytosine

5mC: 5-methylcytosine

MECP2: methyl CpG binding protein 2

P300: histone acetyltransferase P300

PGC1- $\alpha$ : PPAR $\gamma$ coactivator $1-\alpha$

PND: postnatal days

PPAR: peroxisome proliferator-activated receptor

SIRT1: sirtuine 1

SREBP1: sterol regulatory element-binding protein 1

TET: Ten-eleven translocation methylcytosine dioxygenase

WAT: white adipose tissue

iWAT: subcutaneous inguinal

pWAT: visceral perirenal

SVF: stromal vascular fraction 


\section{Abstract}

According to the Developmental Origin of Health and Disease (DOHaD) concept, maternal obesity and accelerated growth in neonates program obesity later in life. White adipose tissue (WAT) has been the focus of developmental programming events, although underlying mechanisms remain elusive. In rodents, WAT development primarily occurs during lactation. We previously reported that adult rat offspring from high-fat diet-fed dams (called HF) showed fat accumulation and decreased PPAR $\gamma$ mRNA levels in WAT. We hypothesized that PPAR $\gamma$ downregulation occurs via epigenetic malprogramming which takes place during adipogenesis. We therefore examined epigenetic modifications in the PPAR $\gamma 1$ and PPAR $\gamma 2$ promoters in perirenal (pWAT) and inguinal (iWAT) fat pads of HF offspring at weaning (postnatal days 21 (PND21) and in adulthood. PND21 is a period characterized by active epigenomic remodeling in the PPAR $\gamma 2$ promoter (DNA hypermethylation and depletion in active histone modification $\mathrm{H} 3 \mathrm{ac}$ and $\mathrm{H} 3 \mathrm{~K} 4 \mathrm{me} 3$ ) in pWAT, consistent with increased DNMT and DNA methylation activities. Adult HF offspring exhibited sustained hypermethylation and histone modification H3ac of the PPAR $\gamma 2$ promoter in both deposits, correlated with persistent decreased PPAR $\gamma 2$ mRNA levels. Consistent with the DOHaD hypothesis, retained epigenetic marks provide a mechanistic basis for the cellular "memory" linking maternal obesity to a predisposition for later adiposity.

Key words: perinatal programming, Developmental Origin of Health and Disease, epigenetic mechanisms, gene expression, fat expansion. 


\section{Introduction}

Epidemiological studies demonstrated that adult-onset metabolic disorders may originate from events taking place during fetal and postnatal development (1). These observations led to the Developmental Origin of Health and Disease (DOHaD) hypothesis also called "developmental programming" (1). In particular, maternal obesity and accelerated growth in neonates program obesity later in life. Numerous studies confirmed that maternal obesity is correlated with increased offspring's adiposity in rodents (2-7) and in human neonates (8). Thus, white adipose tissue (WAT) has been the focus of developmental programming events in a sex- and depot-specific manner (2). In rodents, adipose tissue development occurs mainly during lactation (9-11), although adipose tissue remains to some extent expandable throughout life $(12,13)$. Adipocyte progenitors are highly sensitive to maternal factors. Suboptimal nutritional and hormonal milieu during the perinatal period may affect adipogenesis, resulting in modified growth and persistent changes in the structure and function of WAT (14-16).

However, the mechanisms underlying developmental programming are poorly understood. Because the consequences of the events occurring in early life are maintained throughout adult life, epigenetic modifications are likely to play an important role in this process (17). Epigenetics is defined as heritable changes in gene expression that do not involve changes to the underlying DNA sequence. Epigenetics relate to chromatin modifications, including DNA methylation and histone modifications (18). DNA methylation results from the transfer by DNA methyltransferase (DNMT) of a methyl group to the cytosine residue within $\mathrm{CpG}$ dinucleotides to form 5-methylcytosine (5mC) and serves to establish gene silencing (19). $5 \mathrm{mC}$ both positively and negatively modulates binding of numerous DNA binding proteins including methyl-binding domain (MBD) proteins (MBD2, $\mathrm{MeCP} 2$ ). MBD can recruit protein and chromatin remodeling complexes known to promote 
the formation of a condensed chromatin structure (20). 5-hydroxymethylcytosine (5hmC) is another important cytosine modification catalyzed by the enzymes of the Ten-eleven translocation methylcytosine dioxygenase (TET) family that serves as an intermediate for demethylation. It can also promote chromatin opening at transcriptional regulatory regions (21). Chromatin structure and accessibility are also controlled by histone posttranslational modifications (18). For example, acetylation of histone H3 lysine residues (H3ac) and methylation of $\mathrm{H} 3 \mathrm{~K} 4(\mathrm{H} 3 \mathrm{~K} 4 \mathrm{me} 3)$ are associated with active transcription while methylation of H3K9 (H3K9me3) generally indicates silenced chromatin (18). These histone posttranslational modifications are catalyzed by various enzymes including histone acetyltransferase (HAT) such as KAT2 and P300 as well as histone deacetylase (HDAC) such as SIRT1. Histone-modifying enzyme activity is dependent on intermediary metabolites and hormonal responses (22). Editing of epigenetic marks during critical developmental windows in early life may serve as a memory of exposure to potential environment insults (1). The persistence of these marks throughout life may program permanent changes in gene expression (1).

We previously showed that adult male rat offspring from high-fat diet-fed dams (called HF) displayed higher adiposity (2), hyperleptinemia and elevated leptin gene expression in WAT (25). Persistent leptin upregulation occurs via epigenetic malprogramming during lactation in a depot-specific manner (23). We also showed that adult HF offspring exhibited a decrease in PPAR $\gamma$ gene expression in perirenal (pWAT) fat pad (2). PPAR $\gamma$ is considered the master regulator of adipose tissue promoting all processes involved in adipocyte function and WAT expansion. PPAR $\gamma$ is present in two isoforms, PPAR $\gamma 1$ and PPAR $\gamma 2$, generated by alternative promoter usage (24). PPAR $\gamma 1$ is expressed at low level in many cell types including cells from stromal vascular fraction (SVF) of adipose tissue, whereas the expression of PPAR $\gamma 2$ is mainly restricted to adipocyte (24). Although several studies reported 
dysregulation of PPAR $\gamma$ expression in offspring from obese dams $(3-5,7,25,26)$, scarce data is available about programming mechanisms.

Here, we hypothesized that maternal obesity programs persistent PPAR $\gamma$ downregulation in HF offspring via epigenetic mechanisms malprogramming which take places during WAT development. Thus, we examined epigenetic modifications (i.e., DNA and histone modifications) focusing on both PPAR $\gamma$ promoters as well as activity and expression of chromatin modifying enzymes in pWAT and inguinal (iWAT) fat pads of HF offspring at weaning and 9 months of age.

\section{Materials and methods}

\section{Animals}

Animal use accreditation by the French Ministry of Agriculture (No. 04860) has been granted to our laboratory for experimentation with rats. Experiments were conducted in accordance with the principles of laboratory animal care (European Communities Council Directive of 1986, 86/609/EEC) as previously described $(2,25)$. One-month-old virgin female Wistar rats were purchased from Charles River Laboratories (L'Arbresle, France) and were housed in individual cages in a humidity-controlled room with a 12:12-h light-dark cycle. Food and water were available ad libitum. After two weeks of acclimatization on a control (C) diet $(3.85 \mathrm{kcal} / \mathrm{g}$ with $10 \%$ of total calories as fat consisting of soybean oil $(5.6 \%)$ and lard (4.4\%), $70 \%$ as carbohydrate and 20\% as protein; D12450J, Research Diets, New Brunswick, NJ, USA), female rats were fed either a high-fat (HF) diet $(5.24 \mathrm{kcal} / \mathrm{g}$ with $60 \%$ of total calories as fat consisting of soybean oil (5.6\%) and lard (54.4\%), 20\% as carbohydrate and 20\% as protein; D12492B, Research Diets, New Brunswick, NJ, USA) or a C diet for 16 weeks ( $\mathrm{n}=30$ per group). After mating with a male rat fed a $\mathrm{C}$ diet, 22-week-old pregnant 
females were transferred into individual cages with free access to water and to their respective diets (C or HF diet) throughout gestation and lactation. At parturition, pups were weighed and sexed. Litter size was adjusted to 8 pups per dam (four males and four females). Body weight of pups was assessed on postnatal days 21 (PND21). Only male offspring have been used for further analysis. After weaning, male offspring from $\mathrm{C}$ or HF dams were housed individually with free access to water and $\mathrm{C}$ diet. Body weight of animals was measured weekly until 9 months of age. Male offspring were sacrificed at 2 different stages: PND21 and 9 months of age ( $n=10$ from $C$ or HF dams). To obviate any litter effects, animals used for each experiment were randomly chosen in different litters and only a limited number of animals $(n=1$ to 2$)$ was used from each litter.

\section{Plasma and tissue collections}

21-day-old male neonates were separated from their dams and 9-month-old (9M) male rats were fasted 16 hours before they were sacrificed by decapitation (between 9 and 10 a.m.). Trunk blood samples were collected into prechilled tubes containing EDTA (20 $\mu 1$ of a 5\% solution) and centrifuged at $4000 \mathrm{~g}$ for $10 \mathrm{~min}$ at $4^{\circ} \mathrm{C}$. Plasma was stored at $-20^{\circ} \mathrm{C}$. Fat pads were weighed, frozen in liquid nitrogen and stored at $-80^{\circ} \mathrm{C}$.

\section{Quantification of endocrine parameters}

Plasma hormone levels were evaluated in PND21 and 9M male offspring. Blood glucose was determined using a glucometer (Glucotrend 2; Roche Diagnostics, France). Plasma corticosterone levels were determined by a competitive enzyme immunoassay (Immunodiagnostic Systems Ltd, Boldon, U.K). Plasma insulin concentrations were measured by ELISA (DRG, Internatlukaional, Inc. USA). The assay sensitivity was $0.07 \mathrm{ng} / \mathrm{ml}$ (insulin), $0.55 \mathrm{ng} / \mathrm{ml}$ (corticosterone) and the intra-and inter-assay coefficients of variation 
were $4 \%$ and $9.1 \%$ (insulin), $4.9 \%$ and $7.8 \%$ (corticosterone), respectively. Assay kits were applied to determine the contents of plasma triglycerides (61238 Triglyceride Enzymatique PAP100).

\section{Western blot analysis}

Immunoblotting analysis were carried out as described previously (23). Monoclonal mouse antibody against PPAR $\gamma$ (catalogue no. sc-7273) was purchased from Santa Cruz Biotech (Dallas, TX, USA) and was diluted 1:200. Actin antibody (catalogue no. A2228) was purchased from Sigma Aldrich (Saint Quentin Fallavier, France) and was diluted 1:1000. Anti-mouse IgG, HRP-linked Antibody (catalogue no. 7076) secondary antibodies were purchased from Cell Signalling (Danvers, MA, USA) and were diluted 1:10,000.

\section{Pyrosequencing analysis}

Genomic DNA was extracted from frozen WAT using a DNA extraction kit (DNeasy blood and tissue kit, Qiagen, Courtaboeuf, France) and modified with sodium bisulfite using the EpiTect Fast Bisulfite Conversion kit (Qiagen, Courtaboeuf, France) according to the manufacturer's protocol. The percentage of cytosine methylation was determined by pyrosequencing bisulfite converted DNA using Pyro-Mark Q24 (Qiagen, Courtaboeuf, France). Pyrosequencing primers were designed to amplify PPAR $\gamma 1$ and PPAR $\gamma 2 \mathrm{CpG}$ sites (Table 1). PCR was performed with $20 \mu \mathrm{l}$ final reaction volumes with $1.5 \mathrm{ml}$ of bisulfite DNA (10 ng), $10 \mu \mathrm{l}$ of QuantiTect EurobioGreen PCR Mix Hi-ROX (Eurobio, Les Ulis, France), $7.7 \mu \mathrm{l}$ of $\mathrm{H}_{2} \mathrm{O}$, and $0.4 \mu \mathrm{l}$ of each primer set $(10 \mathrm{mM})$. Sequencing reactions used $10 \mu \mathrm{l}$ of PCR product and $20 \mu \mathrm{l}$ of $0.375 \mathrm{mM}$ sequencing primer (Qiagen, Courtaboeuf, France). Pyrosequencing assays were validated with a DNA methylation scale $(0 \%, 5 \%, 25 \%, 50 \%$, 
75\% and 100\%) (EpigenDX, Hopkinton, USA). Each assay included a bisulfite conversion check to verify full conversion of the DNA.

\section{Chromatin immunoprecipitation}

ChIP assays were performed as previously described (27) with antibodies against H3K4me3, H3ac and H3K9me3 (Abcam, Cambridge, UK, ab8580, ab47915 and ab1773) and IgG (Cell Signaling Technology, Danvers, USA, \#2729) as a negative control. H3ac, $\mathrm{H} 3 \mathrm{~K} 4 \mathrm{me} 3$ and $\mathrm{H} 3 \mathrm{~K} 9 \mathrm{me} 3$ levels were analyzed using immunoprecipitated and input DNA as control.

\section{RNA isolation and real-time PCR}

PPAR $\gamma$ isoforms (PPAR $\gamma 1, \operatorname{PPAR} \gamma 2), \operatorname{PPAR} \gamma$ targets (C/EBP $\alpha$, SREBP1, FAS, DGAT2, LPL, CD36, FABP4, GLUT4, ACOX1, AdipoQ, Resistin), enzymes of the epigenetic machinery (DNMT1, MBD2, MECP2, TET2, TET3, KAT2, P300, HDAC1, SIRT1, LSD1, SUV39) mRNA levels were determined by RT-qPCR using SyberGreen-based chemistry as previously described (2). Cyclophilin A (PpiA) and Ribosomal Protein Lateral Stalk Subunit P1 (RPLP1) were used as reference genes for RT-qPCR. Primer sequences are listed in Table 1.

\section{Global DNA methylation and hydroxymethylation}

Relative levels of global DNA methylation were assessed by me-CpG ELISA using the MethylFlashTM Methylated DNA Quantification Kit (Cat \# P-1034; Epigentek, Mundolsheim, France). Global DNA hydroxymethylation were measured using the Quest 5hmC'M DNA ELISA Kit (Zymo Research, Irvine, CA, USA) according to manufacturer's 

based on a standard curve generated using the kit controls.

\section{Enzyme activity} manufacturer's instructions.

\section{Statistical analysis} significant.

\section{Results}

\section{Effects of maternal obesity on HF offspring metabolic parameters}

instructions. The amount of DNA methylation and DNA hydroxymethylation was calculated

DNMT, TET, HAT and HDAC activities were studied using the EpiQuick DNMT Assay kit (Cat \# P-3001-2; Epigentek, Mundolsheim, France), TET Hydroxylase Activity Quantification kit (Cat \# ab156912; Abcam, Cambridge, UK), EpiQuick HAT Assay kit (Cat \# P-4003-96; Epigentek, Mundolsheim, France) and EpiQuick HDAT Assay kit (Cat \# P4002-96; Epigentek, Mundolsheim, France). These assays were performed according to

All data are expressed as means \pm standard error of the mean (SEM). Statistical analysis was carried out using GraphPad Prism6. A direct comparison between a pair of groups was made using an unpaired Student's t test. $P$ values $<0.05$ was considered statistically

Given that metabolic signals including hormonal signaling pathways play critical roles in determining chromatin structure (28), we assessed the plasma metabolic profile in HF offspring. We previously reported that weaned and adult HF offspring exhibited hyperleptinemia $(2,23)$. Here, we show that serum triacylglycerol and insulin levels were elevated in HF male offspring at PND21 (Table 2). At 9 months of age, HF male offspring 
still displayed hyperinsulinemia and had hypercorticosteronemia (2). No difference in plasma glucose concentration was observed at both stages (Table 2, (2)).

Offspring from obese dams show persistent decreased PPAR $\gamma$ expression levels in adipose tissue

At PND21, HF offspring showed a decrease in PPAR $\gamma$ mRNA and protein expression in pWAT and iWAT, consistent with global reduction in PPAR $\gamma 1$ and PPAR $\gamma 2$ expression (Fig 1A-D). At 9M, among PPAR $\gamma 1$ and PPAR 2 , only the latter showed a persistent dowregulation in both fat pads. The impact of maternal obesity on HF offspring's PPAR $\gamma$ target genes was more pronounced in pWAT at both stages, suggesting a depot-specific programming of adipogenesis and lipogenesis (Fig 1E, F).

\section{Persistent lower PPAR $\gamma$ expression is associated with CpG hypermethylation in the} PPAR $\gamma 2$ promoter of HF offspring

We first assessed whether maternal obesity affects $\mathrm{CpG}$ methylation status of the PPAR $\gamma 1$ and PPAR $\gamma 2$ proximal promoter regions (Fig 2A) in offspring. To do this, we analyzed single CpG sites by bisulfite pyrosequencing. For the PPAR $\gamma 1$ promoter, at PND21, higher 5mC levels with hypermethylation at two out of seven CpG sites analyzed (-364/-346) were observed in pWAT of HF offspring (Fig 2B). Only hypermethylation of CpG -346 persisted in HF offspring at 9 months of age (Fig 2B). No variation in DNA methylation levels were detected in iWAT (Fig 2C). For the PPAR $\gamma 2$ promoter, higher $5 \mathrm{mC}$ levels were measured in both fat pads and stages in HF offspring. Two out of four CpG dinucleotides (215/-199) were similarly affected by maternal obesity. Both CpG were hypermethylated at PND21 whereas only the CpG -199 remained hypermethylated at 9M (Fig 2D and E). 
Consistently, CpG hypermethylation were correlated with PPAR $\gamma$ mRNA levels at PND21 and $9 \mathrm{M}$ in both deposits.

\section{Weaned offspring from obese dams display higher DNMT activity and global DNA methylation in pWAT}

We then assessed whether maternal obesity affects the epigenetic machinery activity in offspring. At PND21, DNMT activity (Fig 2F) and global DNA methylation (Fig 2G) were higher in pWAT, consistent with the $\mathrm{CpG}$ hypermethylation observed in the PPAR $\gamma$ promoters of $\mathrm{HF}$ offspring. No variations in TET activity (Fig 2J) and global hydroxymethylation (Fig 2K) were observed. No changes of DNMT1, MBD2, MECP2, TET2 and TET3 mRNA levels were detected (Fig S1). No gross modifications were observed in iWAT at PND21 and in both fat pads at 9M for all parameters (Fig S1).

Persistent lower PPAR $\gamma$ expression is associated with depletion in H3ac/H3K4me3 in the PPAR $\gamma 2$ promoter of HF offspring

Finally, we assessed whether maternal obesity affects histone modifications in both promoters of offspring. For the PPAR $\gamma 1$ promoter, at PND21, ChIP-qPCR revealed less enrichment of H3ac and H3K4me3 (active marks) in both fat pads of HF offspring (Fig 3AF). These differences were no longer observable at 9 months of age (Fig 3A-F). For the PPAR 2 promoter, at PND21, a reduction of active marks $\mathrm{H} 3 \mathrm{ac}$ and $\mathrm{H} 3 \mathrm{~K} 4 \mathrm{me} 3$ and a tendency towards enrichment of inactive mark H3K9me3 were evidenced only in pWAT of HF offspring (Fig 3A-F). At 9 months of age, persistent reduction of active mark H3ac was measured in both fat pads of HF offspring (Fig 3 A-F). No changes in global histone acetyl transferase and histone deacetylase activities were measured (Fig G and J). No variations of KAT2, P300, HDAC1, SIRT1, LSD1 and SUV39 mRNA levels were evidenced (Fig S1). 


\section{Discussion}

Here, we show, for the first time, that persistent decreased mRNA PPAR $\gamma 2$ levels in adult HF offspring's WAT may occur via epigenomic remodeling in the PPAR $\gamma 2$ promoter which take place during lactation.

We extended our previous work (2) reporting that obesity-prone 9-month-old HF offspring had lower PPAR $\gamma 2$ mRNA expression levels in both pWAT and iWAT fat pads. Given that PPAR $\gamma 2$ promotes adipocyte differentiation and triglyceride storage in WAT (24), it may appear paradoxical that maternal obesity reduces PPAR 22 expression in WAT of HF offspring. However, others have also shown that obesity is associated with a decline in the PPAR $\gamma 2$ activity and expression (29-32). These modifications appear to be strongly associated with the pathogenesis of metabolic syndrome (30-32). The decrease in PPAR $\gamma 2$ gene expression might be seen as an adaptive mechanism to prevent further fat accumulation in WAT (33). It may, in turn, durably change the expression of PPAR $\gamma$ target genes. Consistent with this hypothesis, recent findings have demonstrated that PPAR $\gamma$ downregulation in obese mice is associated with a decrease in genome-wide association occupancy of PPAR $\gamma(31)$.

We previously reported that HF neonates exhibited a rapid weight gain during lactation. At PND21, HF male offspring displayed higher iWAT and pWAT deposit weights with increased leptin mRNA levels, marked adipocyte hypertrophy and hyperplasia. HF 9-monthold male rats showed persistent increased pWAT mass with elevated leptin mRNA levels whereas this "expandable" phenotype was no longer observed in iWAT $(2,23)$. By contrast, both fat pads had persistent lower PPAR $\gamma$ expression. These varying outcomes may reflect difference in postnatal and depot-specific programming. Depot-specific adipogenesis is regulated by the anatomic location, the unique signature of developmental gene expression and the hormonal microenvironment of WAT (35). PPAR $\gamma$ governs biological processes by 
modifying the expression of a large number of target genes. As already reported $(2,25)$, gene expression profiling revealed differences in adipogenic and lipogenic activities between iWAT and pWAT of adult HF offspring, suggesting a depot-specific programming. It may appear paradoxical that persistent reduced PPAR $\gamma 2$ expression was correlated with an increase in expression of genes associated with fat accumulation (i.e., FAS, DGAT2 and LPL) in pWAT. One possible explanation is that regulation of lipogenic genes in adult HF offspring's WAT may occur, at least in part, via additional PPAR $\gamma$-independent signaling pathways. Consistent with this hypothesis, HF adult male offspring exhibited hyperinsulinemia with elevated SREBP-1c mRNA levels within pWAT (2) that might be due for activation of insulin signaling. Indeed, offspring from obese dams showed greater AKT phosphorylation in response to insulin challenge associated with up-regulation of lipogenic pathways in WAT (5).

The underlying molecular mechanisms regulating PPAR $\gamma$ gene expression remain unclear. However, decreased PPAR $\gamma$ expression via modifications of epigenetic mechanisms may play a pivotal role in the development of obesity and diabetes $(29,30,32,35-37)$. Few studies have shown that DNA methylation and histone modifications regulate the expression of PPAR $\gamma$ in WAT $(32,35,36,38-40)$. First, during adipogenesis, DNA demethylation (33) as well as enrichment of active marks H3ac (41) and $\mathrm{H} 3 \mathrm{~K} 4 \mathrm{me} 3(42,43)$ were observed in the PPAR $\gamma$ promoter region that positively regulates gene expression. Second, luciferase reporter assays demonstrated that PPAR $\gamma$ promoter methylation may repress reporter gene expression (33). Third, hypermethylation of the PPAR $\gamma 2$ promoter, which was negatively associated with PPAR $\gamma 2$ expression, was evidenced in visceral WAT of obese animals $(32,36,38,40)$. However, to our knowledge, no data are available regarding PPAR $\gamma$ programming mechanisms in offspring from obese dams. 
We showed that PND21 is a period characterized by active epigenomic remodeling (i.e., higher DNA methylation and lower active histone modification $\mathrm{H} 3 \mathrm{ac}$ and $\mathrm{H} 3 \mathrm{~K} 4 \mathrm{me} 3$ ) of the PPAR $\gamma 2$ promoter in pWAT, consistent with decreased PPAR $\gamma 2$ mRNA expression levels. Higher DNMT activity parallels the increase in global DNA methylation and CpGs methylation in the PPAR $\gamma 2$ promoter. During lactation, adipocyte stem cells are plastic and highly sensitive to maternal factors (44). Thus, maternal obesity and modified milk composition may influence offspring's nutritional and hormonal status (45, 46). Indeed, epigenetic enzyme activities are particularly sensitive to intracellular fluctuation in energy as well as metabolic intermediates (22). In line with this notion, weaned HF offspring exhibited higher plasma leptin levels (2) as well as insulin and triglycerides concentrations. Consistent with epigenomic remodeling, global enzyme activity modifications were observed at PND21. However, the increase in DNMT and DNA methylation activities were restricted to pWAT in weaned HF offspring. It may rely on spatiotemporal developmental differences that occur between depots. The DNMT activity is maximal during adipogenesis (47). In rodents, iWAT depots begin to develop during embryogenesis and the progenitor compartment is established before the first few days of life whereas pWAT depots mainly develop postnatally during lactation which coincides with the period of maximum adipogenesis $(11,48)$. As already suggested $(2,25)$, offspring's pWAT seems to be much more sensitive to maternal obesity. Some of these epigenetic modifications were still observable in the PPAR $\gamma 2$ promoter in adult HF offspring. Sustained epigenetic modifications (i.e., higher DNA methylation and lower active histone modification $\mathrm{H} 3 \mathrm{ac}$ ) were observed in both fat pads of adult HF offspring, consistent with persistent decreased PPAR $\gamma$ gene expression. 5mC is the only known modification that targets the DNA itself. In most cases, the extent of $5 \mathrm{mC}$ of a promoter is inversely correlated with the activity of the respective gene (19). We also showed that the global $5 \mathrm{mC}$ level of the PPAR 22 promoter in adult HF offspring was lower than weaned HF 
pups, suggesting that a demethylation process occurs during development of WAT. The enrichment of H3ac is characteristic of promoter activation (43). A limitation of our work lies in the fact that DNA analysis was performed on entire tissue without distinguishing adipocyte and SVF fractions. Extracts may contain different cell type depending on the stage of development, tissue expansion and physiological states. However, gene expression profiling using several cell markers suggests that the composition of HF offspring's WAT is not modified regardless of the stage of development.

Our results provide compelling evidence that downregulation of PPAR $\gamma$ expression may have developmental origins through epigenetic mechanisms. Thus, editing of early-life epigenetic markings that occurs during development of WAT may persist throughout life. Consistent with the DOHaD hypothesis, retained marks may provide a mechanistic basis for the cellular "memory" linking maternal obesity to a predisposition for later adiposity.

Author contributions: S.L., F.O., D.E., A.G., J.E., C.B. designed the experiments, analyzed data and contributed to discussion and manuscript. C.P., L.B., L.M. performed the experiments. C.L., C.G., J.L., D.V. contributed to discussion.

Acknowledgements: The authors thank Capucine Besenguez, Anne Dickes-Coopman and Valérie Montel for technical assistance during sacrifice.

Funding: This study was supported by grants from the French "Heart and Arteries" Foundation and grants of the French Ministry of Education. Work at INSERM U1011 was supported by grants from the Fondation pour la Recherche Médicale (Equipe labellisée, DEQ20150331724) and "European Genomic Institute for Diabetes" (E.G.I.D., ANR-10LABX-46).

Conflicts of interest: The author declares that he has no conflict of interest that could be perceived as prejudicing the impartiality of the research reported. 


\section{References}

1. Oestreich, A. K. and Moley, K. H. (2017) Developmental and Transmittable Origins of Obesity-Associated Health Disorders. Trends Genet. 33, 399-407

2. Lecoutre, S., Deracinois, B., Laborie, C., Eberlé, D., Guinez, C., Panchenko, P. E., Lesage, J., Vieau, D., Junien, C., Gabory, A., and Breton, C. (2016) Depot- and sexspecific effects of maternal obesity in offspring's adipose tissue. J. Endocrinol. 230, $39-53$

3. $\quad$ Liang, X., Yang, Q., Fu, X., Rogers, C. J., Wang, B., Pan, H., Zhu, M.-J., Nathanielsz, P. W., and Du, M. (2016) Maternal obesity epigenetically alters visceral fat progenitor cell properties in male offspring mice. J. Physiol. 594, 4453-4466

4. Shankar, K., Harrell, A., Liu, X., Gilchrist, J. M., Ronis, M. J. J., and Badger, T. M. (2008) Maternal obesity at conception programs obesity in the offspring. Am. J. Physiol. Regul. Integr. Comp. Physiol. 294, R528-38

5. Borengasser, S. J., Zhong, Y., Kang, P., Lindsey, F., Ronis, M. J. J., Badger, T. M., Gomez-Acevedo, H., and Shankar, K. (2013) Maternal obesity enhances white adipose tissue differentiation and alters genome-scale DNA methylation in male rat offspring. Endocrinology 154, 4113-4125

6. Zambrano, E., Martínez-Samayoa, P. M., Rodríguez-González, G. L., and Nathanielsz, P. W. (2010) Dietary intervention prior to pregnancy reverses metabolic programming in male offspring of obese rats. J. Physiol. 588, 1791-1799

7. Desai, M., Jellyman, J. K., Han, G., Beall, M., Lane, R. H., and Ross, M. G. (2014) Maternal obesity and high-fat diet program offspring metabolic syndrome. Am. J. Obstet. Gynecol. 211, 237.e1-237.e13 
8. Modi, N., Murgasova, D., Ruager-Martin, R., Thomas, E. L., Hyde, M. J., Gale, C., Santhakumaran, S., Doré, C. J., Alavi, A., and Bell, J. D. (2011) The influence of maternal body mass index on infant adiposity and hepatic lipid content. Pediatr. Res. 70, 287-291

9. Greenwood, M. R. and Hirsch, J. (1974) Postnatal development of adipocyte cellularity in the normal rat. J. Lipid Res. 15, 474-483

10. Birsoy, K., Berry, R., Wang, T., Ceyhan, O., Tavazoie, S., Friedman, J. M., and Rodeheffer, M. S. (2011) Analysis of gene networks in white adipose tissue development reveals a role for ETS2 in adipogenesis. Development 138, 4709-4719

11. Han, J., Lee, J.-E., Jin, J., Lim, J. S., Oh, N., Kim, K., Chang, S.-I., Shibuya, M., Kim, H., and Koh, G. Y. (2011) The spatiotemporal development of adipose tissue. Development 138, 5027-5037

12. Joe, A. W. B., Lin, Y., Even, Y., Vogl, a. W., and Rossi, F. M. V. (2009) Depotspecific differences in adipogenic progenitor abundance and proliferative response to high-fat diet. Stem Cells 27, 2563-2570

13. Spalding, K. L., Arner, E., Westermark, P. O., Bernard, S., Buchholz, B. a, Bergmann, O., Blomqvist, L., Hoffstedt, J., Näslund, E., Britton, T., Concha, H., Hassan, M., Rydén, M., Frisén, J., and Arner, P. (2008) Dynamics of fat cell turnover in humans. Nature 453, 783-787

14. Lecoutre, S. and Breton, C. (2015) Maternal nutritional manipulations program adipose tissue dysfunction in offspring. Front. Physiol. 6, 158

15. Lecoutre, S. and Breton, C. (2014) The cellularity of offspring's adipose tissue is programmed by maternal nutritional manipulations. Adipocyte 3, 256-262 
16. Lukaszewski, M.-A., Eberlé, D., Vieau, D., and Breton, C. (2013) Nutritional manipulations in the perinatal period program adipose tissue in offspring. Am. J. Physiol. Endocrinol. Metab. 305, E1195-207

17. Gluckman, P. D., Hanson, M. A., Cooper, C., and Thornburg, K. L. (2008) Effect of in utero and early-life conditions on adult health and disease. N. Engl. J. Med. 359, 61-73

18. Kouzarides, T. (2007) Chromatin modifications and their function. Cell 128, 693-705

19. Jones, P. A. and Takai, D. (2001) The role of DNA methylation in mammalian epigenetics. Science 293, 1068-1070

20. Medvedeva, Y. A., Khamis, A. M., Kulakovskiy, I. V, Ba-Alawi, W., Bhuyan, M. S. I., Kawaji, H., Lassmann, T., Harbers, M., Forrest, A. R., Bajic, V. B., and FANTOM consortium. (2014) Effects of cytosine methylation on transcription factor binding sites. BMC Genomics 15, 119

21. Tahiliani, M., Koh, K. P., Shen, Y., Pastor, W. A., Bandukwala, H., Brudno, Y., Agarwal, S., Iyer, L. M., Liu, D. R., Aravind, L., and Rao, A. (2009) Conversion of 5methylcytosine to 5-hydroxymethylcytosine in mammalian DNA by MLL partner TET1. Science 324, 930-935

22. Öst, A. and Pospisilik, J. A. (2015) Epigenetic modulation of metabolic decisions. Curr. Opin. Cell Biol. 33, 88-94

23. Lecoutre, S., Oger, F., Pourpe, C., Butruille, L., Marousez, L., Dickes-Coopman, A., Laborie, C., Guinez, C., Lesage, J., Vieau, D., Junien, C., Eberlé, D., Gabory, A., Eeckhoute, J., and Breton, C. (2017) Maternal obesity programs increased leptin gene expression in rat male offspring via epigenetic modifications in a depot-specific manner. Mol. Metab. 6, 922-930 
24. Tontonoz, P. and Spiegelman, B. M. (2008) Fat and Beyond: The Diverse Biology of PPAR $\gamma$. Annu. Rev. Biochem. 77, 289-312

25. Samuelsson, A.-M., Matthews, P. a, Argenton, M., Christie, M. R., McConnell, J. M., Jansen, E. H. J. M., Piersma, A. H., Ozanne, S. E., Twinn, D. F., Remacle, C., Rowlerson, A., Poston, L., and Taylor, P. D. (2008) Diet-induced obesity in female mice leads to offspring hyperphagia, adiposity, hypertension, and insulin resistance: a novel murine model of developmental programming. Hypertension 51, 383-392

26. Yang, Q.-Y., Liang, J.-F., Rogers, C. J., Zhao, J.-X., Zhu, M.-J., and Du, M. (2013) Maternal obesity induces epigenetic modifications to facilitate Zfp423 expression and enhance adipogenic differentiation in fetal mice. Diabetes 62, 3727-3735

27. Oger, F., Dubois-Chevalier, J., Gheeraert, C., Avner, S., Durand, E., Froguel, P., Salbert, G., Staels, B., Lefebvre, P., and Eeckhoute, J. (2014) Peroxisome proliferatoractivated receptor $\alpha$ regulates genes involved in insulin/insulin-like growth factor signaling and lipid metabolism during adipogenesis through functionally distinct enhancer classes. J. Biol. Chem. 289, 708-722

28. Lu, C. and Thompson, C. B. (2012) Metabolic regulation of epigenetics. Cell Metab. 16, $9-17$

29. Guilherme, A., Virbasius, J. V., Puri, V., and Czech, M. P. (2008) Adipocyte dysfunctions linking obesity to insulin resistance and type 2 diabetes. Nat. Rev. Mol. Cell Biol. 9, 367-377 
30. Soccio, R. E., Li, Z., Chen, E. R., Foong, Y. H., Benson, K. K., Dispirito, J. R., Mullican, S. E., Emmett, M. J., Briggs, E. R., Peed, L. C., Dzeng, R. K., Medina, C. J., Jolivert, J. F., Kissig, M., Rajapurkar, S. R., Damle, M., Lim, H.-W., Won, K.-J., Seale, P., Steger, D. J., and Lazar, M. A. (2017) Targeting PPAR $\gamma$ in the epigenome rescues genetic metabolic defects in mice. J. Clin. Invest. 127, 1451-1462

31. Zhang, B., Berger, J., Hu, E., Szalkowski, D., White-Carrington, S., Spiegelman, B. M., and Moller, D. E. (1996) Negative regulation of peroxisome proliferator-activated receptor-gamma gene expression contributes to the antiadipogenic effects of tumor necrosis factor-alpha. Mol. Endocrinol. 10, 1457-1466

32. Fujiki, K., Kano, F., Shiota, K., and Murata, M. (2009) Expression of the peroxisome proliferator activated receptor gamma gene is repressed by DNA methylation in visceral adipose tissue of mouse models of diabetes. BMC Biol. 7, 38

33. Ortega, F. J., Mayas, D., Moreno-Navarrete, J. M., Catalán, V., Gómez-Ambrosi, J., Esteve, E., Rodriguez-Hermosa, J. I., Ruiz, B., Ricart, W., Peral, B., Fruhbeck, G., Tinahones, F. J., and Fernández-Real, J. M. (2010) The gene expression of the main lipogenic enzymes is downregulated in visceral adipose tissue of obese subjects. Obesity (Silver Spring). 18, 13-20

34. Hepler, C. and Gupta, R. K. (2017) The expanding problem of adipose depot remodeling and postnatal adipocyte progenitor recruitment. Mol. Cell. Endocrinol. 445, $95-108$

35. Yan, Z., Zhang, H., Maher, C., Arteaga-Solis, E., Champagne, F. A., Wu, L., McDonald, J. D., Yan, B., Schwartz, G. J., and Miller, R. L. (2014) Prenatal Polycyclic Aromatic Hydrocarbon, Adiposity, Peroxisome Proliferator-Activated Receptor (PPAR) $\gamma$ Methylation in Offspring, Grand-Offspring Mice. PLoS One 9, e110706 
36. Zwamborn, R. A. J., Slieker, R. C., Mulder, P. C. A., Zoetemelk, I., Verschuren, L., Suchiman, H. E. D., Toet, K. H., Droog, S., Slagboom, P. E., Kooistra, T., Kleemann, R., and Heijmans, B. T. (2017) Prolonged high-fat diet induces gradual and fat depotspecific DNA methylation changes in adult mice. Sci. Rep. 7, 43261

37. Zhang, B., Berger, J., Hu, E., Szalkowski, D., White-Carrington, S., Spiegelman, B. M., and Moller, D. E. (1996) Negative regulation of peroxisome proliferator-activated receptor-gamma gene expression contributes to the antiadipogenic effects of tumor necrosis factor-alpha. Mol. Endocrinol. 10, 1457-1466

38. Jiao, F., Yan, X., Yu, Y., Zhu, X., Ma, Y., Yue, Z., Ou, H., and Yan, Z. (2016) Protective effects of maternal methyl donor supplementation on adult offspring of high fat diet-fed dams. J. Nutr. Biochem. 34, 42-51

39. Kosaka, K., Kubota, Y., Adachi, N., Akita, S., Sasahara, Y., Kira, T., Kuroda, M., Mitsukawa, N., Bujo, H., and Satoh, K. (2016) Human adipocytes from the subcutaneous superficial layer have greater adipogenic potential and lower PPAR- $\gamma$ DNA methylation levels than deep layer adipocytes. Am. J. Physiol. - Cell Physiol. 311, C322-C329

40. Sun, Y. N., Gao, Y., Qiao, S. P., Wang, S. Z., Duan, K., Wang, Y. X., Li, H., and Wang, N. (2014) Epigenetic DNA methylation in the promoters of Peroxisome Proliferator-Activated Receptor in chicken lines divergently selected for fatness. $J$. Anim. Sci. 92, 48-53

41. Salma, N., Xiao, H., Mueller, E., and Imbalzano, A. N. (2004) Temporal Recruitment of Transcription Factors and SWI / SNF Chromatin-Remodeling Enzymes during Adipogenic Induction of the Peroxisome Proliferator-Activated Receptor $\mathbb{Z}$ Nuclear Hormone Receptor. Society 24, 4651-4663 
42. Cho, Y.-W., Hong, S., Jin, Q., Wang, L., Lee, J.-E., Gavrilova, O., and Ge, K. (2009) Histone methylation regulator PTIP is required for PPARgamma and C/EBPalpha expression and adipogenesis. Cell Metab. 10, 27-39

43. Mikkelsen, T. S., Xu, Z., Zhang, X., Wang, L., Gimble, J. M., Lander, E. S., and Rosen, E. D. (2010) Comparative epigenomic analysis of murine and human adipogenesis. Cell 143, 156-169

44. Tang, Q. Q. and Lane, M. D. (2012) Adipogenesis: from stem cell to adipocyte. Annu. Rev. Biochem. 81, 715-736

45. Sun, B., Purcell, R. H., Terrillion, C. E., Yan, J., Moran, T. H., and Tamashiro, K. L. K. (2012) Maternal high-fat diet during gestation or suckling differentially affects offspring leptin sensitivity and obesity. Diabetes 61, 2833-2841

46. Vogt, M. C., Paeger, L., Hess, S., Steculorum, S. M., Awazawa, M., Hampel, B., Neupert, S., Nicholls, H. T., Mauer, J., Hausen, a C., Predel, R., Kloppenburg, P., Horvath, T. L., and Brüning, J. C. (2014) Neonatal insulin action impairs hypothalamic neurocircuit formation in response to maternal high-fat feeding. Cell 156, 495-509

47. Londoño Gentile, T., Lu, C., Lodato, P. M., Tse, S., Olejniczak, S. H., Witze, E. S., Thompson, C. B., and Wellen, K. E. (2013) DNMT1 is regulated by ATP-citrate lyase and maintains methylation patterns during adipocyte differentiation. Mol. Cell. Biol. 33, 3864-3878

48. Berry, D. C., Stenesen, D., Zeve, D., and Graff, J. M. (2013) The developmental origins of adipose tissue. Development 140, 3939-3949 


\begin{tabular}{|c|c|c|c|c|c|}
\hline \multicolumn{2}{|r|}{ RT-qPCR primer sequences } & Targeted mRNA & \multicolumn{2}{|r|}{ Pyrosequencing primer sequences } & Targeted regions \\
\hline Forward & TTGGCCATATTTATAGCTGTCATTATT & \multirow{2}{*}{ PPARY } & Forward & ATGTTGGTTAAATGAGTTTATTTAGTG & \multirow{3}{*}{$\begin{array}{c}\text { PPARy2 promoter } \\
\# 1\end{array}$} \\
\hline Reverse & TGTCCTGGATGGGCTTCA & & Reverse & Biotin-ACACTATCCTAATTAAAAACCAACTA & \\
\hline Forward & GCACTGCCTATGAGCACTTC & \multirow{2}{*}{ PPARY1 } & Sequence & ATTGAATGTGTGGG & \\
\hline Reverse & GTGGCCTGTTGTAGAGTTGG & & Forward & TTGTTTAGTTTTGTGGAATGTGGAGAGTAG & \multirow{3}{*}{$\begin{array}{c}\text { PPARy2 promoter } \\
\# 2\end{array}$} \\
\hline Forward & GCTGCAGCGCTAAATTCATC & \multirow{2}{*}{ PPARү2 } & Reverse & Biotin-ACTATCTCCCСAATAАCCСАCACATTCA & \\
\hline Reverse & GCTGATTCCGAAGTTGGTGG & & Sequence & TGTTGAATA-AATTATTTTAGAAGT & \\
\hline Forward & CCAATCACGCAATAGTTCTGG & \multirow{2}{*}{$A \operatorname{cox}$} & Forward & GGGGGATTATTGTTATGTGATATGTT & \multirow{3}{*}{$\begin{array}{c}\text { PPARy2 promoter } \\
\# 3\end{array}$} \\
\hline Reverse & CGCTGTATCGTATGGCGAT & & Reverse & Biotin-ATAAAAAAAATTAAAACCCTCCСТAAAAAT & \\
\hline Forward & CAGGAGATGCTGGAATGACA & \multirow{2}{*}{ AdipoQ } & Sequence & ATTAGGTTATTTATGTGATAAGG & \\
\hline Reverse & CTACGCTGAATGCTGAGTGAT & & Forward & AACTATCACCAAATCCACACAAT & \multirow{5}{*}{$\begin{array}{c}\text { PPARy1 promoter } \\
\# 1\end{array}$} \\
\hline Forward & TGCATGAATTAGTTGAACCAGGCCA & \multirow{4}{*}{$C / E B P \alpha$} & Reverse & Biotin-CCCAAAACAATCTAACACCAACCATAA & \\
\hline Reverse & CCACAGTTCCGATCGCAGCCC & & Sequence 1 & GGTTTTTTTAGAAGGTGTT & \\
\hline Forward & AGTTGACCAGTGACAATGACCG & & Sequence 2 & GTGAGAGTTAGGAGTAGGGTA & \\
\hline Reverse & TCAGGCAGCTGGCGGAAG & & Sequence 3 & TTTGATAGGAAAGTTAGGT & \\
\hline Forward & AGGCCTTGATGGTTTCTATCCA & \multirow{2}{*}{ DGAT2 } & & ChIP-qPCR primer sequences & Targeted regions \\
\hline Reverse & GCTGCCCTTCCCCAATTAAC & & Forward & ACAGTTTTCAGAGAGGGGCT & \multirow{2}{*}{ PPARY1 promoter } \\
\hline Forward & TAGTTCGGTGGCTACGAGGA & \multirow{2}{*}{ DNMT1 } & Reverse & CGACAGTGACCCCATTTTCC & \\
\hline Reverse & CGTTTAGCGGGACCCTTGAA & & Forward & ACAGTTCACACCCCTCACAA & \multirow[b]{2}{*}{ PPARy2 promoter } \\
\hline Forward & GACCTGGAAACTCGTCTCCA & \multirow{2}{*}{ FABP4 } & Reverse & TGGCACTGTCCTGATTGAGA & \\
\hline Reverse & CATACCGGCCACTTTCCTGG & & Forward & AGAGCTGAAAGAGGGCAAGA & \multirow{2}{*}{ Control A } \\
\hline Forward & GGACATGGTCACAGACGATGAC & \multirow{2}{*}{ FAS } & Reverse & GTCTCTCCTGCCCTCAAACT & \\
\hline Reverse & GTCGAACTTGGACAGATCCTTCA & & Forward & CAGGCTGTTGAGTGGGTAGA & \multirow{2}{*}{ Control B } \\
\hline Forward & AGGCACCCTCACTACCCTTT & GLUT4 & Reverse & GGGCCACTGTTGCCATTTTA & \\
\hline
\end{tabular}

\begin{tabular}{l|l|l} 
Reverse & ATAGCCCTTTTCCTTCCCAA & \multirow{2}{*}{ GLUT4 }
\end{tabular}

\begin{tabular}{l|l|l} 
Forward & CCAGAAGCCAAAGGGGTCAA & \\
\cline { 1 - 2 }
\end{tabular}

\begin{tabular}{l|l} 
Reverse & TGCGCTGGTCCCTATCTAGT \\
\hline
\end{tabular}

\begin{tabular}{l|l|l} 
Forward & ACTCCCATCTTCAGTCCTTC
\end{tabular}

\begin{tabular}{ll} 
Reverse & CTTCCTCCTCTCTCCTGGC \\
\hline
\end{tabular}

\begin{tabular}{l|l} 
Forward & AAGGTCATCTTCTGTGCCA \\
\hline Reverse
\end{tabular}

\begin{tabular}{ll} 
Reverse & CAGCCCGACTTCTTCAGAGA \\
\hline
\end{tabular}

Forward GGCAAGAGCGATGTCTACTA

Reverse $\quad$ CTGGACCGACTCCTTGAAGA

\begin{tabular}{l|l}
\hline Forward & CAGCTCCAACAGGATTCCATGGT \\
\hline
\end{tabular}

\begin{tabular}{l|l} 
Reverse & TGATGTCTCTGCTTTGCCTGCCT \\
\hline
\end{tabular}

Forward AGATTCAGAGGGCAGCAGAGAC

Reverse GCCATAGGAGGTGGGTTCATAC

\begin{tabular}{l|l} 
Forward & AGACTTCAGCTCCCTACTG \\
\hline
\end{tabular}

\begin{tabular}{l|l} 
Reverse & CTAGTGACGGTTGTGCCTT \\
\hline
\end{tabular}

$\begin{array}{ll}\text { Forward } & \text { CTGTTTCCTGTGGGATACCTGACT }\end{array}$

Reverse $\quad$ ATCGAACATGGCTTGAGGATC T

\begin{tabular}{l|l} 
Forward & CATCGACTACATCCGCTTCTTACA
\end{tabular}

$\begin{array}{ll}\text { Reverse } & \text { GTCTTTCAGTGATTTGCTTTTGTGA }\end{array}$

Forward

Reverse

AATCGCCTTCGGATTCAGACACTC

Forward TCAGCAACACCTTCATCACAA

\begin{tabular}{l|l} 
Reverse & TTTTCCTTGGGTGGTTTGTCA
\end{tabular}

\begin{tabular}{ll} 
Forward & ATTCATGTGCCAGGGTGGT \\
\hline
\end{tabular}

Reverse $\quad$ GATGCCAGGACCTGTATGCT

\begin{tabular}{ll} 
Forward & GACGGTCACGGAGGATAAGATC \\
\hline
\end{tabular} 
Table 2

Plasma parameters of weaned male offspring from obese dams fed either a control (C) or a high-fat (HF) diet

\begin{tabular}{|l|c|c|c|}
\hline & \multicolumn{3}{|c|}{ Mariable Offspring PND21 } \\
\hline & C & HF & $\begin{array}{c}\text { Maternal } \\
\text { diet effect } \\
p \text { value }\end{array}$ \\
\hline Glucose $(\mathrm{dg} / \mathrm{ml})$ & $168.22 \pm 5.49$ & $171.14 \pm 2.54$ & $\mathrm{~ns}$ \\
\hline Triacyglycerol $(\mathrm{mg} / \mathrm{dl})$ & $210.9 \pm 11.28$ & $281.9 \pm 13.10$ & $*$ \\
\hline Insulin $(\mu \mathrm{U} / \mathrm{ml})$ & $34.35 \pm 5.94$ & $60.99 \pm 5.49$ & $*$ \\
\hline Corticosterone $(\mathrm{ng} / \mathrm{ml})$ & $221.21 \pm 16.87$ & $216.63 \pm 20.84$ & $\mathrm{~ns}$ \\
\hline
\end{tabular}

590

All data are presented as means +/- SEM. Data were analyzed using Student's $t$ test. Effects of 
Figure legends

Figure 1: Maternal obesity induces persistent lower PPAR $\gamma$ expression in adipose tissue of offspring

PPAR $\gamma$ expression was assessed in male offspring from dams fed a control diet (called C) or high-fat diet-fed dams (called HF) on postnatal days 21 (PND21) and 9 months of age (9M). PPAR $\gamma$, PPAR $\gamma 1$ and PPAR $\gamma 2$ mRNA levels were determined in pWAT (A) and iWAT (B) by RT-qPCR. Representative Western blot of PPAR $\gamma(55 \mathrm{KDa})$ and $\beta$-Actin (43 KDa) were indicated in pWAT (C) and iWAT (D). mRNA levels of PPAR $\gamma$ target genes were determined in pWAT $(\mathbf{E})$ and iWAT $(\mathbf{F})$ by RT-qPCR. Relative gene expression in the C group at PND21 was set to 1. Ppia and Rplp1 were used as standard genes. All data are presented as means +/- SEM. Data were analyzed using Student's $t$ test. Effects of maternal obesity at PND21 $(* \mathrm{P}<0.05)$ and at $9 \mathrm{M}(\# \mathrm{P}<0.05) . \mathrm{n}=5-10$ per group.

Figure 2: Persistent lower PPAR $\gamma$ expression is associated with CpG hypermethylation in the PPAR 2 promoter of HF offspring

Epigenetic modifications were assessed in male $\mathrm{C}$ and $\mathrm{HF}$ offspring in two fat pads (pWAT and iWAT) at PND21 and 9M. Schematic positions and sequences of rat PPAR $\gamma 1$ and PPAR $\gamma 2$ promoters were shown (A). CpG methylation in $\operatorname{PPAR} \gamma 1$ promoter $(\mathbf{B}, \mathbf{C})$ and PPAR $\gamma 2$ promoter $(\mathbf{D}, \mathbf{E})$ were assessed by bisulfite pyrosequencing in pWAT $(\mathbf{B}, \mathbf{D})$ and iWAT $(\mathbf{C}, \mathbf{E})$. DNMT activity from nuclear protein $(\mathbf{F})$ and global DNA methylation $(\mathbf{G})$ were assessed in pWAT and iWAT. TET activity from nuclear protein $(\mathbf{H})$ and global DNA hydroxymethylation (I) were assessed in pWAT and iWAT. All data are presented as means 
+/- SEM. Data were analyzed using Student's $t$ test. Effects of maternal obesity at PND21 (*P $<0.05)$ and at $9 \mathrm{M}(\#<0.05) . \mathrm{n}=5$ per group.

\section{Figure 3: Persistent lower PPAR $\gamma$ expression is associated with depletion in} H3ac/H3K4me3 in the PPAR $\gamma 2$ promoter of HF offspring

Epigenetic modifications were assessed in male $\mathrm{C}$ and $\mathrm{HF}$ offspring in two fat pads (pWAT and iWAT) at PND21 and 9M. Histone modifications were measured by ChIP assays with antibodies against H3ac (A, B), H3K4me3 (active mark) (C, D) and H3K9me3 (inactive mark) $(\mathbf{E}, \mathbf{F})$ in pWAT $(\mathbf{A}, \mathbf{C}, \mathbf{E})$ and iWAT $(\mathbf{B}, \mathbf{D}, \mathbf{F})$. HAT $(\mathbf{G})$ and HDAC $(\mathbf{H})$ activities were assessed from nuclear protein of pWAT and iWAT. All data are presented as means $+/-$ SEM. Data were analyzed using Student's $t$ test. Effects of maternal obesity at PND21 (*P < $0.05)$ and at $9 \mathrm{M}(\# \mathrm{P}<0.05) . \mathrm{n}=5$ per group.

(1)

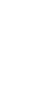


A

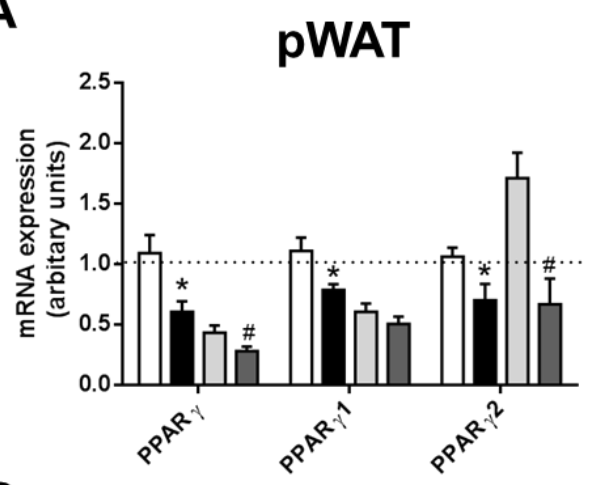

C

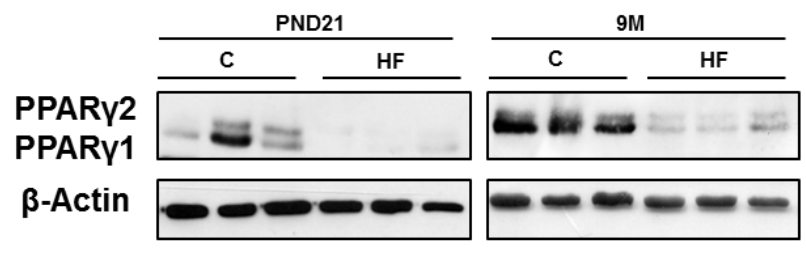

E

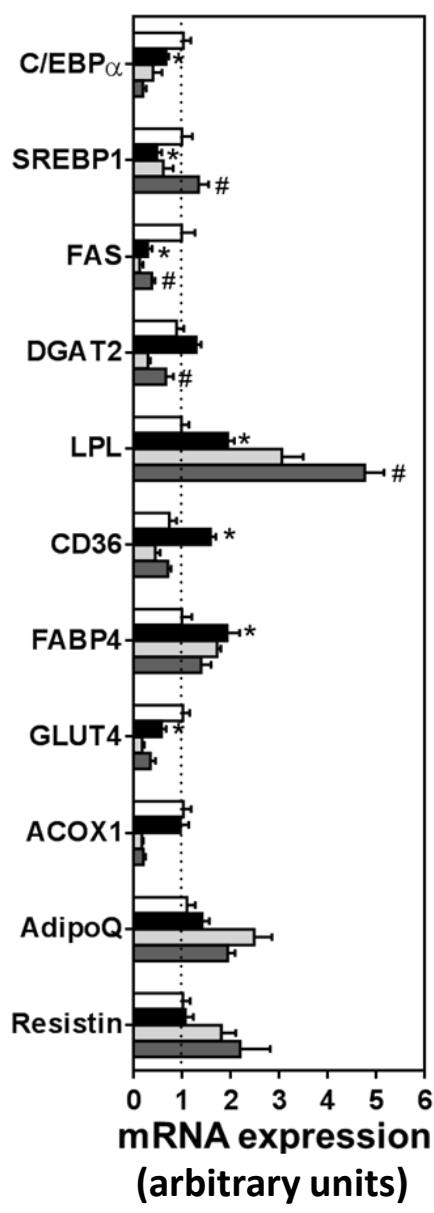

B

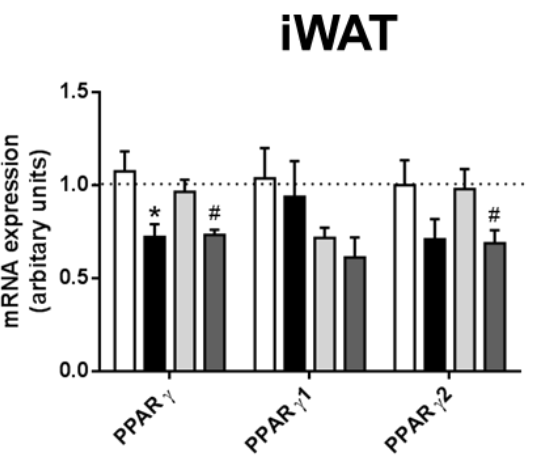

D

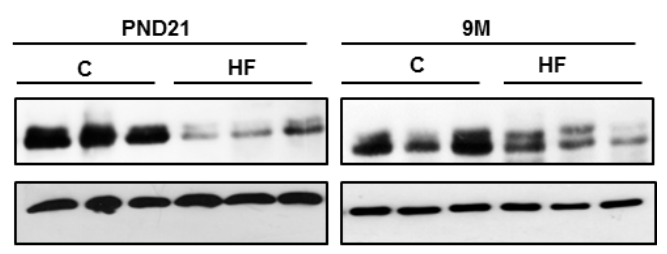

F

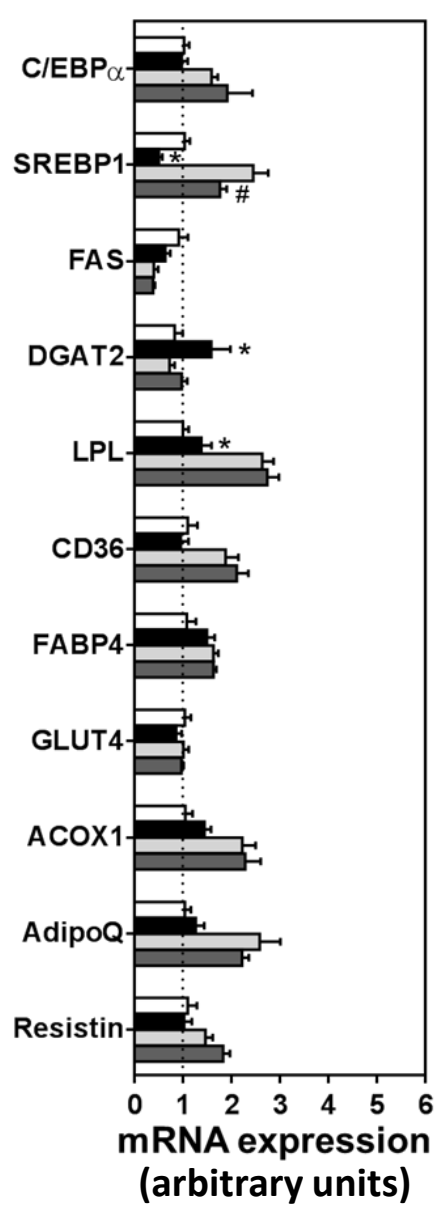


A

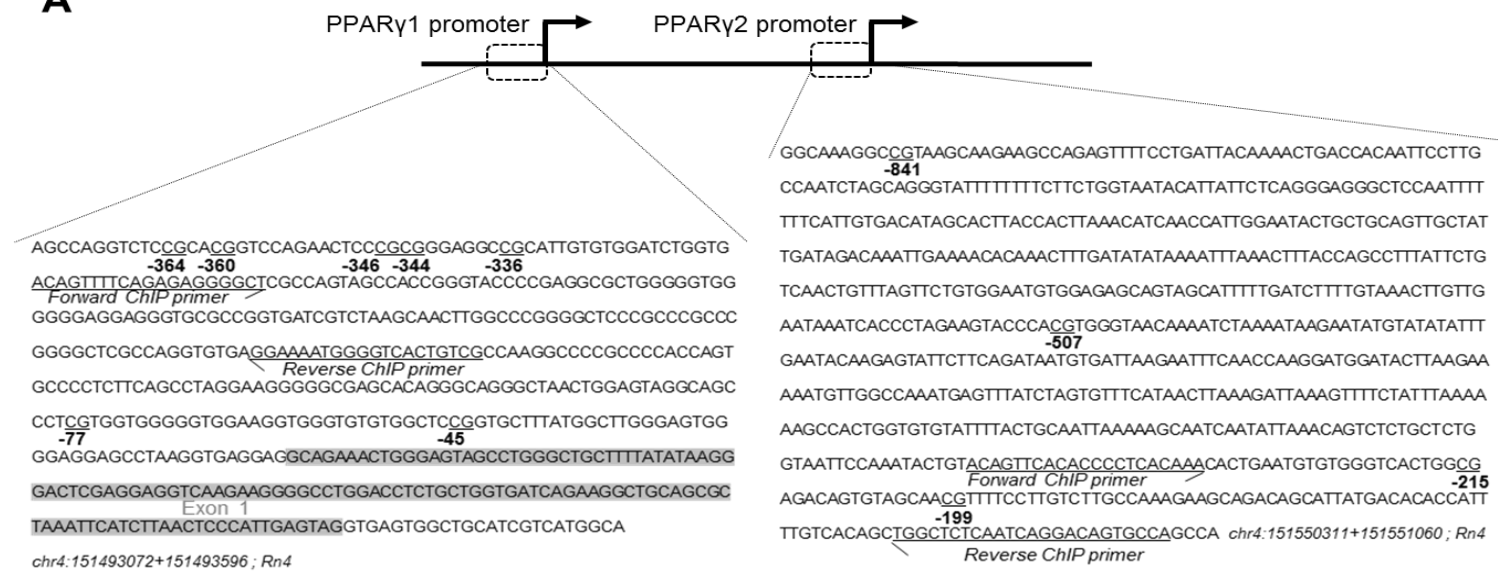

B
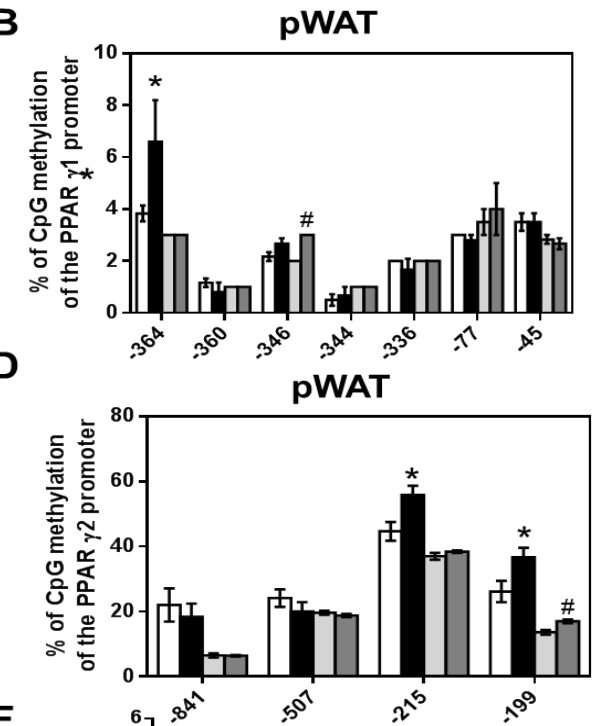

F
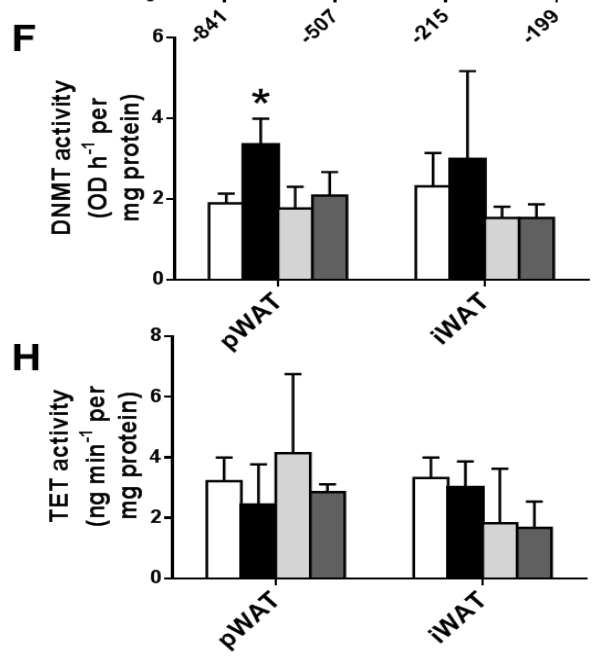

$\square$ C-PND21

HF-PND21

$\square$ C-9M

HF-9M

C

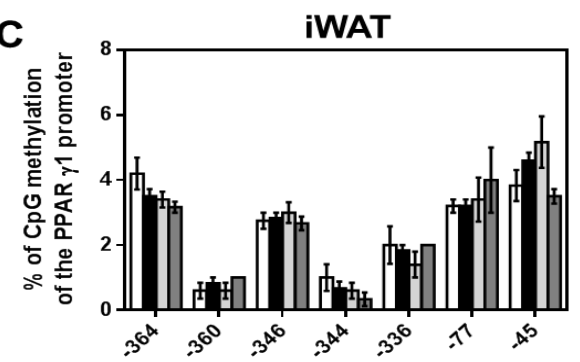

E

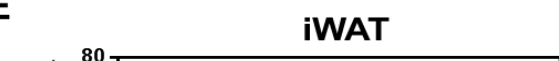

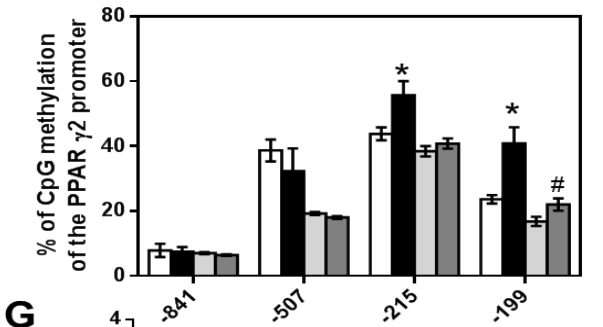

G
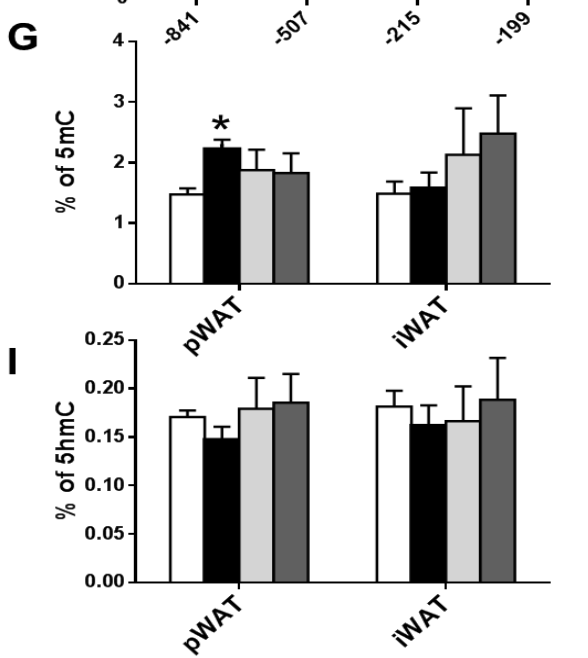

Figure 2 


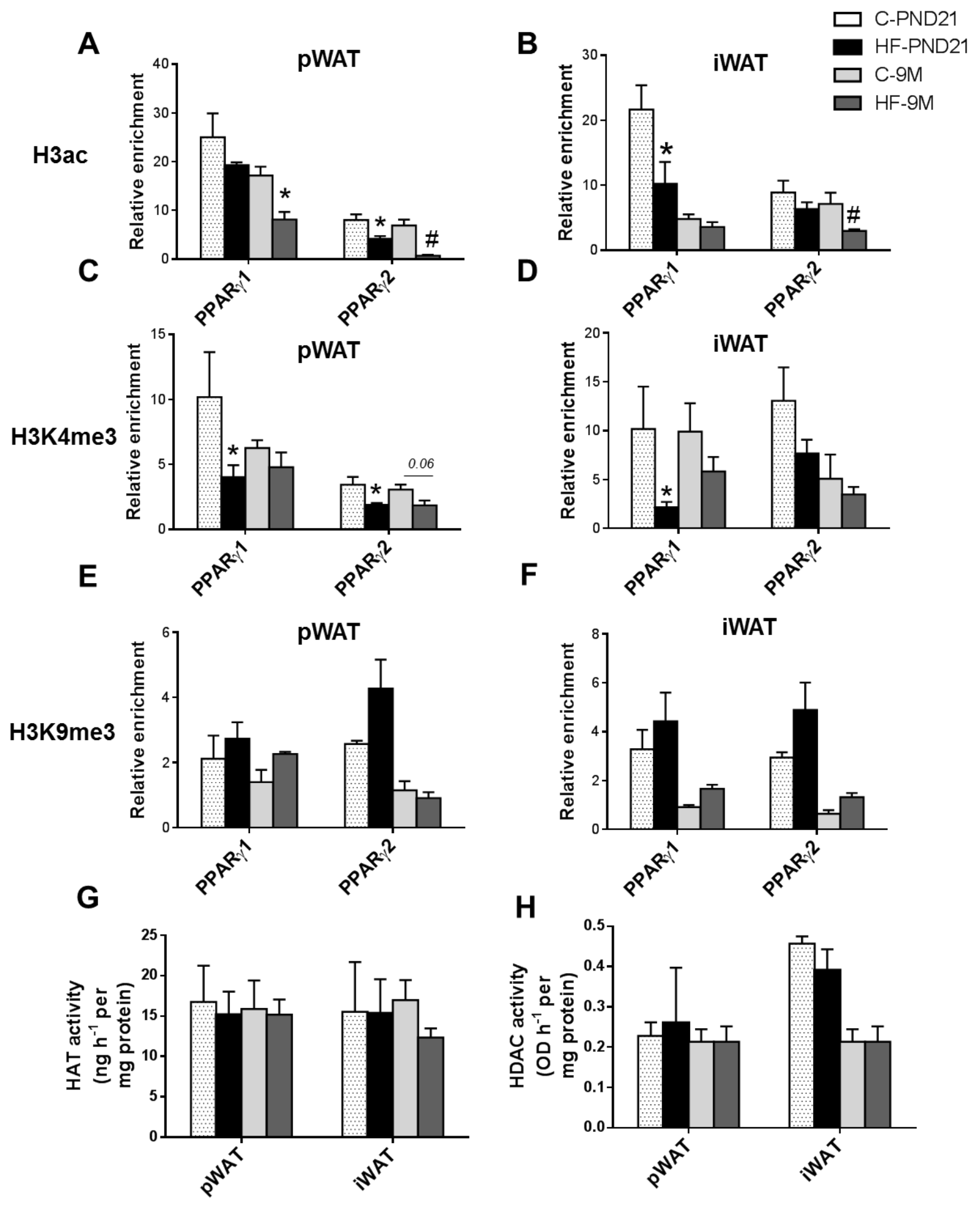

Figure 3 